\title{
Communication \\ Preparation and Performance Analysis of Ag/ZnO Humidity Sensor
}

\author{
Peng Li, Shuguo Yu (D) and Hongyan Zhang * \\ School of Physical Science and Technology, Xinjiang University, Urumqi 830046, China; lip@xju.edu.cn (P.L.); \\ yushuguo0818@163.com (S.Y.) \\ * Correspondence: zhy@xju.edu.cn
}

\begin{abstract}
Highly sensitive silver (Ag) modified zinc oxide $(\mathrm{ZnO})$ humidity sensors were prepared by hydrothermal synthesis and the mechanism was studied. Experimental results show that Ag-modified $\mathrm{ZnO}$ can effectively enhance the performance of a humidity sensor. Large number of oxygen vacancies and many active sites are generated on the surface when molar ratio of $\mathrm{Ag}^{+}$to $\mathrm{Zn}^{2+}$ is 1:100, which can accelerate the decomposition of water molecules on surface of the material, thereby improving the response of humidity sensor. Moreover, the linearity of ZnO humidity sensor is greatly improved by silver nanoparticles. Compared with previously reported ZnO-based humidity sensors, Ag/ZnO humidity sensors have a better response (151,700\%), good linearity, low hysteresis (3\%), and short response/recovery time (36/6s). At the same time, it is found that the light had little effect on the performance of $\mathrm{Ag} / \mathrm{ZnO}$. Therefore, this kind of $\mathrm{ZnO}$ sensor with stable performance and excellent performance is expected to be used in the detection of relative humidity in conventional environments.
\end{abstract}

Keywords: Ag-modified $\mathrm{ZnO}$; humidity sensor; response; light

check for

updates

Citation: Li, P.; Yu, S.; Zhang, H. Preparation and Performance Analysis of Ag/ZnO Humidity Sensor. Sensors 2021, 21, 857. https://doi.org/10.3390/ s21030857

Received: 14 November 2020 Accepted: 25 December 2020 Published: 28 January 2021

Publisher's Note: MDPI stays neutral with regard to jurisdictional claims in published maps and institutional affiliations.

\section{Introduction}

Recently, humidity sensors have been developed rapidly and have attracted much attention in many fields such as agriculture, food safety, industrial production, medical treatment and so on [1-3]. Among the many sensor types, resistive sensors are the most common sensitive components. The applicability is greatly expanded due to its simple manufacturing, high detection sensitivity, and low production cost. A resistive humidity sensor is obtained by covering a substrate with a film made of a humidity-sensitive material. The resistance of the component will change when a water molecule is adsorbed onto the sensitive film under different relative humidity environments, so as to achieve the purpose of relative humidity detection [4,5]. In terms of the structure of the resistance humidity sensor, the selection of sensitive materials is still the key to improving the performance of the relative humidity sensor. Recently, metal oxides, polymers, and carbon materials are often used in the design and manufacture of humidity sensors. Among many materials, $\mathrm{SnO}_{2}[6,7], \mathrm{TiO}_{2}[8,9], \mathrm{WO}_{3}[10,11], \mathrm{ZnO}[12,13]$ and other metal oxide semiconductor materials [14-16] are widely used in the preparation of sensors because of their simple preparation process, low price, wide source of raw materials and good biological compatibility. Among them, $\mathrm{ZnO}$ nanostructures have become a potential sensing material due to their high activity and large specific surface area $[17,18]$, which has attracted widespread attention. Furthermore, $\mathrm{ZnO}$ nanostructures exhibit morphologically dependent sensing characteristics $[19,20]$, so the morphological structure also plays a key role in the performance of $\mathrm{ZnO}$ sensors.

$\mathrm{ZnO}$ as a sensitive material shows poor linearity and low sensitivity for relative humidity detection, which limits its application as a humidity sensor. With the in-depth research requiring the sensitivity of the humidity sensor, the linearity stability needs to be further improved. To improve the responsiveness of $\mathrm{ZnO}$ humidity sensors, noble metal doping 
$(\mathrm{Au}, \mathrm{Ag}, \mathrm{Pd}$ and $\mathrm{Pt})$ is a frequently used method [21,22]. Silver $(\mathrm{Ag})$ is one of the most conductive materials, and its low cost and good catalytic performance have been widely used in sensors. The introduction of modified silver nanoparticles into $\mathrm{ZnO}$ can control the surface morphology and crystal structure of $\mathrm{ZnO}$, which is expected to improve the performance of humidity sensors. Moreover, after $\mathrm{Ag}$ is introduced into $\mathrm{ZnO}$, the adsorption sites on the surface of the material will increase, and the number of surface defects will increase. On the one hand, large adsorption sites and high surface defects can make water molecules adsorbed on surface of the material decompose quickly, and hence improves the response speed of the sensor. On the other hand, silver particles have good electrical conductivity, which is beneficial to improve linearity of the sensor, so $\mathrm{Ag} / \mathrm{ZnO}$ composite material can provide a new idea for the preparation of high-performance humidity sensors.

In this work, we successfully prepared an $\mathrm{Ag} / \mathrm{ZnO}$ humidity sensor using the hydrothermal method, and response of the sensor under different light conditions was studied. Experimental results show that an $\mathrm{Ag} / \mathrm{ZnO}$ humidity sensor exhibits high sensitivity, low hysteresis and short response/recovery time when a molar ratio of $\mathrm{Ag}^{+}$to $\mathrm{Zn}^{2+}$ is 1:100. This is mainly because in this case there are a large number of oxygen vacancies and active sites on the surface of $\mathrm{ZnO}$. Under the action of oxygen vacancies and active sites, the water molecules on the surface of the $\mathrm{Ag} / \mathrm{ZnO}-2$ humidity sensor are rapidly decomposed, thereby increasing response of the humidity sensor. Compared with pure $\mathrm{ZnO}$, such a relative humidity sensor based on modified silver has better linearity.

\section{Experimental}

\subsection{Experimental Materials and Test Equipment}

The main materials and reagents used in this experiment were zinc acetate dihydrate $\left(\mathrm{Zn}\left(\mathrm{CH}_{3} \mathrm{COOH}\right)_{2} \cdot 2 \mathrm{H}_{2} \mathrm{O}\right)$, ethanol $\left(\mathrm{C}_{2} \mathrm{H}_{5} \mathrm{OH}\right)$, ethanolamine (MEA) and silver nitrate hexahydrate $\left(\mathrm{AgNO}_{3} \cdot 6 \mathrm{H}_{2} \mathrm{O}\right)$. All the above materials were purchased from Sangon Biotech (Shanghai, China, www.sangon.com). The chemical reagents used were of analytical grade, and deionized water (DI) was used throughout the experiments. Morphology of the sample was tested by a field emission scanning electron microscope (FESEM (Hitachi, Japan)). Crystal structure of the material was tested by an X-ray powder diffractometer XRD (Bruker, Karlsruhe, Germany). Absorption spectrum was tested by UV-Vis (PerkinElmer, Waltham, MA, USA) spectrophotometer. Elemental composition of the sample was analyzed by X-ray photoelectron spectroscopy (XPS) (Thermo Fisher Scientific Corporation, Waltham, MA, USA). The electrochemical characteristics of the humidity sensor were tested on the Zennium workstation (CIMPS-2, Zahner, Kronach, Germany).

\subsection{Preparation of $\mathrm{ZnO}$ Microparticles}

All reagents were of analytical grade without further purification. The specific experimental details are described as follows. Zinc acetate dihydrate $(0.230 \mathrm{~g})$ and sodium hydroxide $(0.364 \mathrm{~g})$ were mixed together in $25 \mathrm{~mL}$ of deionized water and $10 \mathrm{~mL}$ of ethanol was magnetically stirred at $65^{\circ} \mathrm{C}$ for $10 \mathrm{~min}$ to form a transparent solution. $1 \mathrm{~mL}$ of MEA was added dropwise to the above mixed solution and stirred for $2 \mathrm{~h}$. Finally, the gel was dried in a $60^{\circ} \mathrm{C}$ drying oven for $2 \mathrm{~h}$, and the annealing process was carried out in a tube furnace at $600{ }^{\circ} \mathrm{C}$ for $2 \mathrm{~h}$ under nitrogen protection.

\subsection{Preparation of $A g$-doped $\mathrm{ZnO}$ Microparticles $(\mathrm{Ag} / \mathrm{ZnO})$}

In total, $2.3 \mathrm{~g}$ of $\mathrm{Zn}\left(\mathrm{CH}_{3} \mathrm{COOH}\right)_{2} \cdot 2 \mathrm{H}_{2} \mathrm{O}$ and $\mathrm{AgNO}_{3}$ with different molar ratios (molar ratio of $\mathrm{Ag}+$ to $\mathrm{Zn}^{2+}$ is 1:10, 1:100, 1:1000) were dissolved into a mixed solution of $25 \mathrm{~mL}$ of deionized water and $10 \mathrm{~mL}$ of ethanol, heated up to $65^{\circ} \mathrm{C}$ with magnetically stirring for $10 \mathrm{~min}, 1 \mathrm{~mL}$ of ethanolamine (MEA) was added and magnetically stirred for $2 \mathrm{~h}$ to obtain a uniform white sol, which was left to stand at room temperature for $48 \mathrm{~h}$. Then, the gel was dried in a $60{ }^{\circ} \mathrm{C}$ drying oven for $2 \mathrm{~h}$. Finally, chemical vapor deposition (CVD) was used to anneal for $2 \mathrm{~h}$ at $600^{\circ} \mathrm{C}$ under nitrogen protection in a tube furnace. We named the above samples $\mathrm{Ag} / \mathrm{ZnO}-1, \mathrm{Ag} / \mathrm{ZnO}-2$ and $\mathrm{Ag} / \mathrm{ZnO}-3$, respectively. 


\subsection{Relative Humidity Sensitive Characteristics Test}

During the measurement of humidity characteristics, different humidity environments were controlled by saturated salt solutions of $\mathrm{LiCl}, \mathrm{MgCl}_{2}, \mathrm{Mg}\left(\mathrm{NO}_{3}\right)_{2}, \mathrm{NaCl}, \mathrm{KCl}$ and $\mathrm{KNO}_{3}$, corresponding to relative humidity of $11 \%, 33 \%, 54 \%, 75 \%, 85 \%$ and $95 \%$ [19]. In conventional humidity measurement, humidity usually refers to relative humidity, which is a generally accepted method of measuring humidity, and so in this article, relative humidity is used for measurement. Sprayed $\mathrm{ZnO}, \mathrm{Ag} / \mathrm{ZnO}$ and water was mixed on the Ag-Pd interdigital electrode (IDE) and then put it in a $60^{\circ} \mathrm{C}$ constant temperature oven to dry for $1 \mathrm{~h}$ to form a humidity sensor. Throughout the measurement processes, the test voltage was set to be $\mathrm{AC} 1 \mathrm{~V}$, measurement frequency was $40 \mathrm{~Hz}$ to $100 \mathrm{kHz}$, and the whole test process was carried out at room temperature $\left(25^{\circ} \mathrm{C}\right)$. The test details of the humidity sensor are shown in Figure 1.

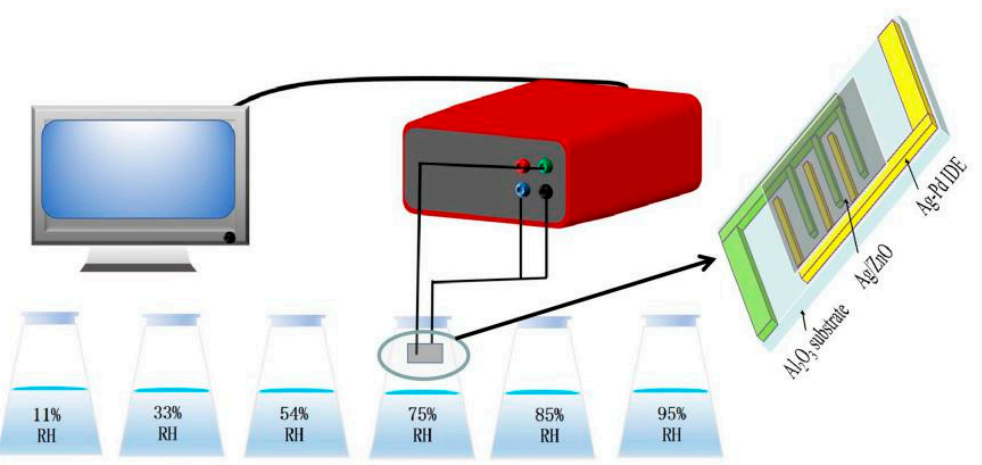

Figure 1. The testing process of the $\mathrm{Ag} / \mathrm{ZnO}$ humidity sensor.

\section{Results and Discussion}

Figure 2 shows XRD patterns of $\mathrm{ZnO}, \mathrm{Ag} / \mathrm{ZnO}-1, \mathrm{Ag} / \mathrm{ZnO}-2$ and $\mathrm{Ag} / \mathrm{ZnO}-3$, which can be used to analyze crystal structures of all the samples. The diffraction peaks of all samples at $2 \theta$ of $31.8^{\circ}, 34.2^{\circ}, 36.3^{\circ}, 47.5^{\circ}, 56.7^{\circ}, 62.7^{\circ}, 66.4^{\circ}, 68.1^{\circ}$ and $69.1^{\circ}$ are similar to the ones of typical hexagonal wurtzite structures consistent (JCPDS No. 36-1451). Compared with $\mathrm{ZnO}$, the weaker diffraction peaks corresponding to (111), (200), and (311) crystal planes in $\mathrm{Ag} / \mathrm{ZnO}-1, \mathrm{Ag} / \mathrm{ZnO}-2$ and $\mathrm{Ag} / \mathrm{ZnO}-3$ belong to $\mathrm{Ag}$ crystals of face centered cubic (fcc) structure. The appearance of (111), (200), and (311) crystal plane diffraction peaks indicate the successful recombination of $\mathrm{Ag}$ and $\mathrm{ZnO}$. Compared with $\mathrm{Ag} / \mathrm{ZnO}-1$, the intensity of diffraction peak of $\mathrm{Ag}$ in $\mathrm{Ag} / \mathrm{ZnO}-2$ and $\mathrm{Ag} / \mathrm{ZnO}-3$ gradually becomes weaker, which is mainly due to the gradually decreasing Ag content in the sample.

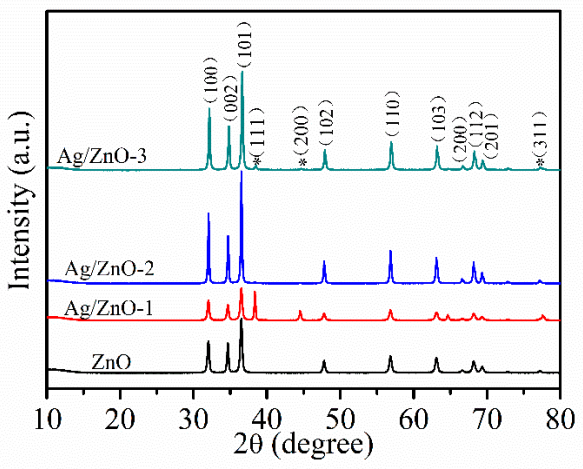

Figure 2. $\mathrm{XRD}$ spectra of $\mathrm{ZnO}, \mathrm{Ag} / \mathrm{ZnO}-1, \mathrm{Ag} / \mathrm{ZnO}-2$ and $\mathrm{Ag} / \mathrm{ZnO}-3$.

Figure 3 shows the scanning electron microscope images of $\mathrm{ZnO}$ and $\mathrm{Ag} / \mathrm{ZnO}$. In Figure $3 \mathrm{a}, \mathrm{b}, \mathrm{ZnO}$ and $\mathrm{Ag} / \mathrm{ZnO}-1$ exhibit irregular microparticles with a diameter of about 50-70 $\mathrm{nm}$ and 130-160 nm, and these irregular microparticles are agglomerated. $\mathrm{Ag} / \mathrm{ZnO}-2$ are irregular microparticles with a diameter of about $70-90 \mathrm{~nm}$, and the particles are evenly 
distributed and dispersed without agglomeration (Figure 3c). The structure of $\mathrm{Ag} / \mathrm{ZnO}-2$ is evenly distributed and more dispersed. Compared with the other three structures, it can provide more adsorption sites for water molecules, making more water molecules adsorb to the surface of the material. This structure plays a vital role in the humidity sensor. In Figure $3 \mathrm{~d}, \mathrm{Ag} / \mathrm{ZnO}-3$ is also of irregular particles with a diameter of about $60-70 \mathrm{~nm}$, and the particles are slightly agglomerated. In general, compared with the other three structures, $\mathrm{Ag} / \mathrm{ZnO}-2$ may show better humidity sensing performance.

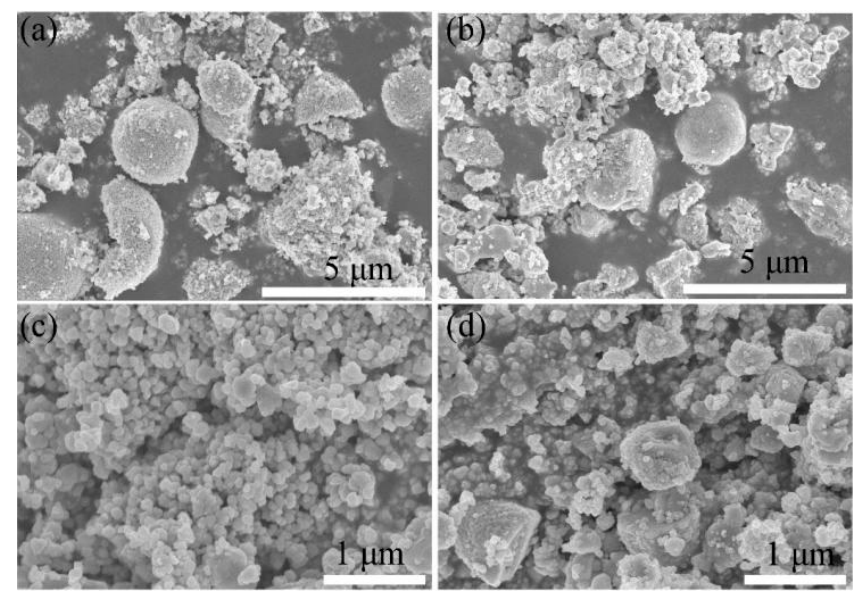

Figure 3. SEM of (a) $\mathrm{ZnO}$ and (b) $\mathrm{Ag} / \mathrm{ZnO}-1$, (c) $\mathrm{Ag} / \mathrm{ZnO}-2$ and (d) $\mathrm{Ag} / \mathrm{ZnO}-3$.

In Figure 4, the optical absorption characteristics of all the samples are given by UV-vis absorption spectrum. In the ultraviolet region as shown in Figure 4a, the strong absorptions for all of $\mathrm{ZnO}, \mathrm{Ag} / \mathrm{ZnO}-1, \mathrm{Ag} / \mathrm{ZnO}-2$ and $\mathrm{Ag} / \mathrm{ZnO}-3$ indicate that all the samples are wide bandgap direct semiconductors. The strong absorption peak located at $350 \mathrm{~nm}$ belongs to intrinsic absorption of $\mathrm{ZnO}$. Because $\mathrm{ZnO}$ has strong absorption in ultraviolet light and weak absorption in visible light, there is a sharp decrease at $390 \mathrm{~nm}$. Compared with $\mathrm{ZnO}$, there is blue shift for all the absorption peaks of $\mathrm{Ag} / \mathrm{ZnO}-1, \mathrm{Ag} / \mathrm{ZnO}-2$ and $\mathrm{Ag} / \mathrm{ZnO}-3$, which indicates that the band gap of the samples gradually becomes smaller. The absorption peaks of $\mathrm{Ag} / \mathrm{ZnO}-1, \mathrm{Ag} / \mathrm{ZnO}-2$ and $\mathrm{Ag} / \mathrm{ZnO}-3$ at $480 \mathrm{~nm}$ are gradually weakened with the decreasing of $\mathrm{Ag}$ content. Figure $4 \mathrm{~b}$ shows the band gaps of $\mathrm{ZnO}$, $\mathrm{Ag} / \mathrm{ZnO}-1, \mathrm{Ag} / \mathrm{ZnO}-2$ and $\mathrm{Ag} / \mathrm{ZnO}-3$ calculated by the Kubelka-Munk formula $(\alpha \mathrm{h} v)^{2}$ $=\mathrm{A}\left(\mathrm{h} v-\mathrm{E}_{\mathrm{g}}\right)$, where $\alpha$ is the absorption coefficient, $\mathrm{h} v$ is the photon energy, $\mathrm{E}_{\mathrm{g}}$ is the band gap energy, and $\mathrm{A}$ is a constant. The band gaps of $\mathrm{ZnO}, \mathrm{Ag} / \mathrm{ZnO}-1, \mathrm{Ag} / \mathrm{ZnO}-2$ and $\mathrm{Ag} / \mathrm{ZnO}-3$ are $3.00 \mathrm{eV}, 1.94 \mathrm{eV}, 2.80 \mathrm{eV}$ and $2.92 \mathrm{eV}$, respectively. With the increase of the doped Ag content, the forbidden band width of the sample gradually decreases, which is consistent with the analysis result as in Figure 4a. The lower the band gap energy of the material, the lower the energy it should generate, which is beneficial to improving the conductivity of the humidity sensor.
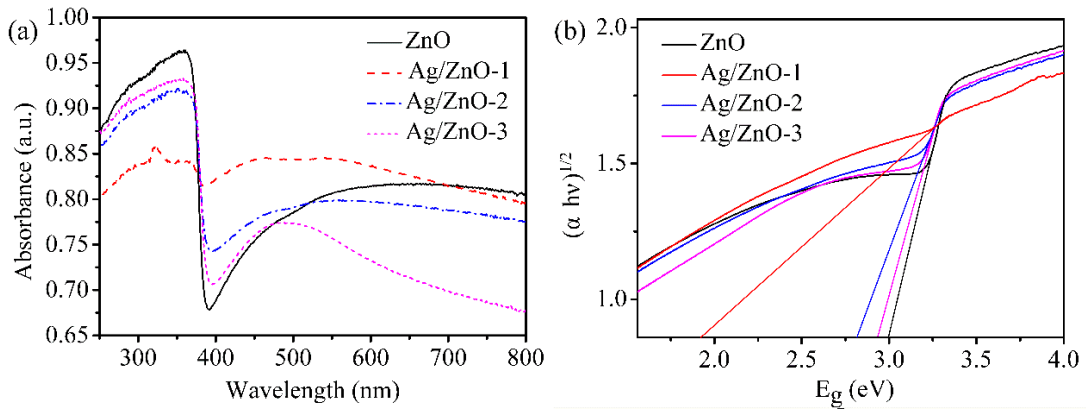

Figure 4. (a) UV-vis absorption spectrum and (b) $\mathrm{E}_{\mathrm{g}}$ of $\mathrm{ZnO}, \mathrm{Ag} / \mathrm{ZnO}-1, \mathrm{Ag} / \mathrm{ZnO}-2$ and $\mathrm{Ag} / \mathrm{ZnO}-3$. 
In order to further determine the state of oxygen on the material surface, the $\mathrm{O} 1 \mathrm{~s}$ peak XPS spectra of $\mathrm{ZnO}$ and $\mathrm{Ag} / \mathrm{ZnO}$ are fitted in Figure 5. The $\mathrm{O} 1 \mathrm{~s}$ of all samples are fitted to three peaks, namely $\mathrm{O}_{1}, \mathrm{O}_{2}$ and $\mathrm{O}_{3}$. The $\mathrm{O}_{1}$ peak at $529.3 \mathrm{eV}$ is the $\mathrm{O}^{2-}$ bonded to $\mathrm{Zn}^{2+}$, the $\mathrm{O}_{2}$ peak at $530.2 \mathrm{eV}$ is the defect oxygen on the zinc oxide surface, and the $\mathrm{O}_{3}$ peak at $531.2 \mathrm{eV}$ is some adsorbed oxygen on the zinc oxide surface. After calculation, it was found that the defect oxygen area ratios of the four samples are $27.8 \%, 24.1 \%, 38.9 \%$ and $25.6 \%$, respectively. It can be seen that the number of oxygen vacancies on the $\mathrm{Ag} / \mathrm{ZnO}-2$ surface is the largest. It is well known that oxygen vacancies can accelerate the decomposition of water molecules into conductive ions [23,24]. For $\mathrm{Ag} / \mathrm{ZnO}-2$, recombination of $\mathrm{Ag}$ leads to the most oxygen vacancies to dissociate water molecules adsorbed on the surface of zinc oxide to form $\mathrm{H}_{3} \mathrm{O}^{+}$conductive ions, hence improving humidity sensitivity.
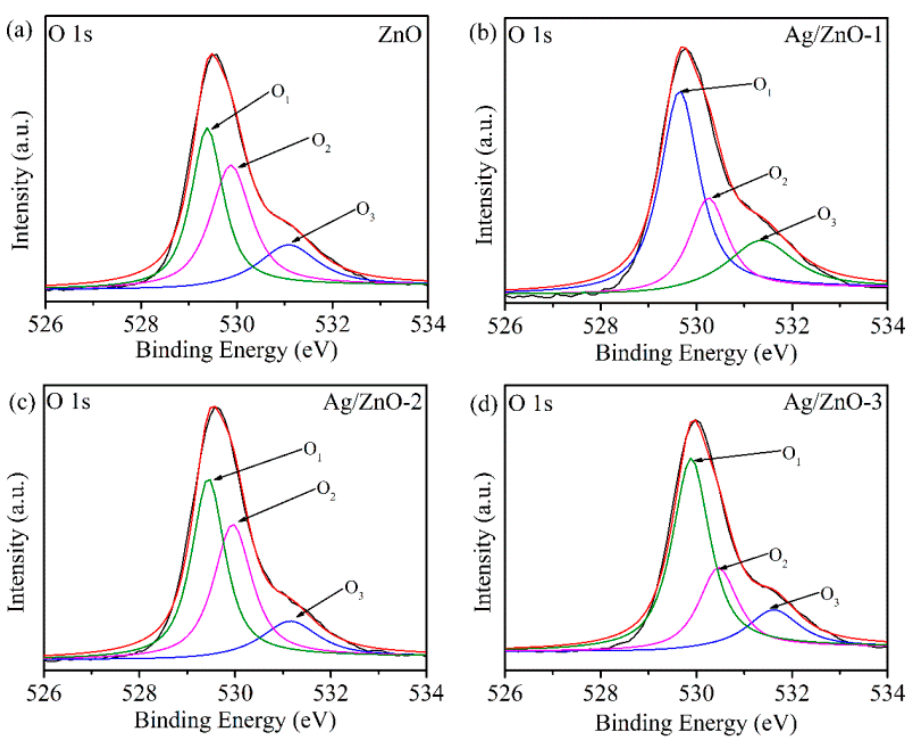

Figure 5. XPS spectra of $\mathrm{O} 1 \mathrm{~s}$ of (a) $\mathrm{ZnO}$, (b) Ag/ZnO-1, (c) Ag/ZnO-2 and (d) Ag/ZnO-3.

Figure 6a shows the response curves of $\mathrm{ZnO}, \mathrm{Ag} / \mathrm{ZnO}-1, \mathrm{Ag} / \mathrm{ZnO}-2$ and $\mathrm{Ag} / \mathrm{ZnO}-3$. We found that the performance of humidity sensor became worse with the increase of $\mathrm{Ag}^{+}$ concentration. The humidity sensor shows a good response and the resistance changes more than three orders of magnitude when the molar ratio of $\mathrm{Ag}^{+}: \mathrm{Zn}^{2+}$ is $0.01(\mathrm{Ag} / \mathrm{ZnO}-2)$. It is reported that $\frac{R_{11 \%}-R_{95 \%}}{R_{95 \%}} \times 100 \%$ is defined as the response of the sensor $[14,25]$, so it can be calculated that the responses of $\mathrm{ZnO}, \mathrm{Ag} / \mathrm{ZnO}-1, \mathrm{Ag} / \mathrm{ZnO}-2$ and $\mathrm{Ag} / \mathrm{ZnO}-3$ are $64,300 \%, 1510 \%, 151,700 \%$ and $10,200 \%$, respectively. Compared with the $\mathrm{rGO} / \mathrm{ZnO}$ nanorods/Cu humidity sensor (97.79\%) reported by Kuntal et al. and the Er:ZnO humidity sensor (impedance change of about three orders of magnitude) reported by Zhang et al., the $\mathrm{Ag} / \mathrm{ZnO}-2$ humidity sensor showed a better response [26,27]. The response of $\mathrm{Ag} / \mathrm{ZnO}-2$ is probably due to the large amount of oxygen vacancy on surface of $\mathrm{ZnO}$ when molar ratio of $\mathrm{Ag}^{+}: \mathrm{Zn}^{2+}$ is 0.01 . As an active site, oxygen vacancy can accelerate the decomposition of water molecules adsorbed on surface of $\mathrm{ZnO}$, which makes more water molecules decompose into conductive ions, thus improving the response of $\mathrm{Ag} / \mathrm{ZnO}-2$ humidity sensor. In addition, the uniformly dispersed sheet structure of $\mathrm{Ag} / \mathrm{ZnO}-2$ can also be used for more water molecules to be adsorbed, which increases the amount of water absorbed on surface of the material and can also enhance the performance of the humidity sensor. Compared with $\mathrm{Ag} / \mathrm{ZnO}-2, \mathrm{ZnO}, \mathrm{Ag} / \mathrm{ZnO}-1$ and $\mathrm{Ag} / \mathrm{ZnO}-3$ have poorer response. On one hand, there are not enough oxygen vacancies on the surface, which limits the decomposition of water molecules. On the other hand, $\mathrm{ZnO}, \mathrm{Ag} / \mathrm{ZnO}-1$ and $\mathrm{Ag} / \mathrm{ZnO}-3$ particles are agglomerated, resulting in relatively few adsorbed water molecules, which in turn affects humidity sensor response. 

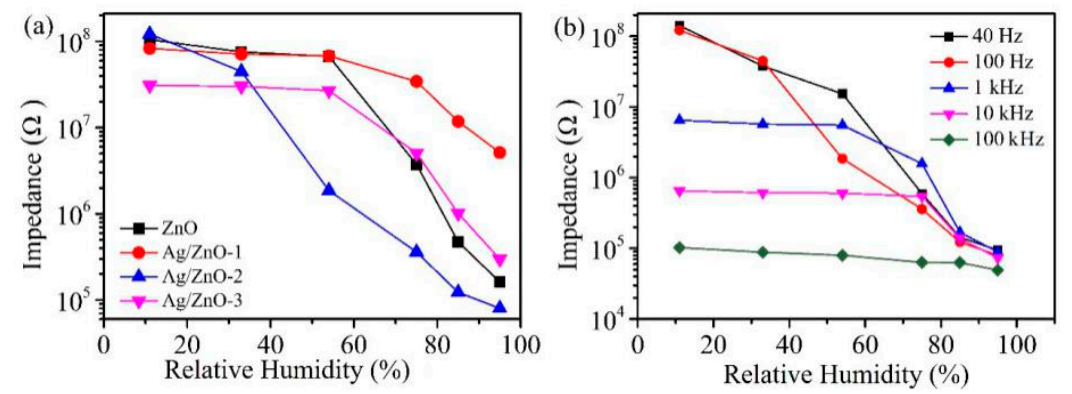

Figure 6. (a) Resistance changes of $\mathrm{ZnO}, \mathrm{Ag} / \mathrm{ZnO}-1, \mathrm{Ag} / \mathrm{ZnO}-2$ and $\mathrm{Ag} / \mathrm{ZnO}-3$ at $11 \% \mathrm{RH}-95 \% \mathrm{RH}$; (b) $\mathrm{Ag} / \mathrm{ZnO}-2$ humidity sensor responses at $40 \mathrm{~Hz}, 100 \mathrm{~Hz}, 1 \mathrm{kHz}, 10 \mathrm{kHz}$ and $100 \mathrm{kHz}$.

In order to determine the optimal test frequency of the $\mathrm{Ag} / \mathrm{ZnO}-3$ humidity sensor, we tested the response of $\mathrm{Ag} / \mathrm{ZnO}-1$ at $40 \mathrm{~Hz}, 100 \mathrm{~Hz}, 1 \mathrm{kHz}, 10 \mathrm{kHz}$ and $100 \mathrm{kHz}$ under different relative humidity, and the test results are shown in Figure 6b. Although the response of $\mathrm{Ag} / \mathrm{ZnO}-2$ humidity sensor is high at $40 \mathrm{~Hz}$, the overall linearity of the sensor is poor, so $40 \mathrm{~Hz}$ cannot be selected as the best test frequency. At $1 \mathrm{kHz}, 10 \mathrm{kHz}$ and $100 \mathrm{kHz}$, the response and linearity of the sensor are poor because the water molecules cannot be polarized at high frequencies, and the polarization of water molecules adsorbed by the sensor cannot keep up with the direction of electric field change in the high-frequency region. Only when the test frequency is $100 \mathrm{~Hz}, \mathrm{Ag} / \mathrm{ZnO}-3$ humidity sensor shows high response and good linearity. Therefore, we choose $100 \mathrm{~Hz}$ as the best test frequency, and all subsequent tests are conducted at this frequency.

The hysteresis, response/recovery time, and repeatability of the humidity sensor are also the main factors that determine the performance of the sensor. Figure 7a shows the hysteresis test of $\mathrm{Ag} / \mathrm{ZnO}-2$ humidity sensor in the range of $11 \% \mathrm{RH}$ to $95 \% \mathrm{RH}$. When the environmental $\mathrm{RH}$ changes from $11 \%$ to $95 \% \mathrm{RH}$, the process of the sensor continuously adsorbing water molecules is an adsorption process. Conversely, when the $\mathrm{RH}$ is changed from $95 \%$ to $11 \% \mathrm{RH}$, the process by which the sensor continuously separates from water molecules is a desorption process. It can be observed that the resistance value of adsorption process is almost higher than that of desorption process in whole detection range, which is mainly caused by the endothermic desorption process of water molecules on $\mathrm{Ag} / \mathrm{ZnO}-2$ surface is slower than the exothermic adsorption process. The hysteresis error can be calculated according to $\gamma \mathrm{H}= \pm \Delta \mathrm{H}_{\max } / 2 \mathrm{~F}_{\mathrm{FS}}$, where $\Delta \mathrm{H}_{\max }$ is the maximum hysteresis value and $\mathrm{F}_{\mathrm{FS}}$ is the full range output of the sensor [28]. It can be calculated that the maximum hysteresis error of the $\mathrm{Ag} / \mathrm{ZnO}$ humidity sensor is $3 \%$. Compared with previously reported $\mathrm{ZnO}$ humidity sensor, the $\mathrm{Ag} / \mathrm{ZnO}-2$ humidity sensor also has a low hysteresis error. $\mathrm{Ag} / \mathrm{ZnO}-2$ humidity sensor response/recovery time and repeatability test is shown in Figure $7 \mathrm{~b}$. It is well known that the time required for the sensor response or recovery process resistance to reach $90 \%$ is defined as response or recovery [29]. Response time and recovery time of $\mathrm{Ag} / \mathrm{ZnO}-2$ humidity sensor are $36 \mathrm{~s}$ and $6 \mathrm{~s}$, respectively. The faster response and recovery speed of $\mathrm{Ag} / \mathrm{ZnO}-2$ is mainly due to the abundant oxygen vacancies on its surface, which causes a large number of water molecules to be decomposed quickly. In addition, the distribution of $\mathrm{Ag} / \mathrm{ZnO}-2$ is uniform, and the absence of agglomeration will also cause water molecules to quickly detach from the surface of the material. We have continuously tested the adsorption and analysis process of $\mathrm{Ag} / \mathrm{ZnO}-2$ humidity sensor in two cycles, and we can see that adsorption and desorption process of the sensor in the two cycles are almost the same, which shows that $\mathrm{Ag} / \mathrm{ZnO}-2$ humidity sensor has good repeatability. All the above properties show that $\mathrm{Ag} / \mathrm{ZnO}-2$ humidity sensor has the potential to develop a high-performance humidity sensor, and also provides a new idea for the preparation of a new humidity sensor. 

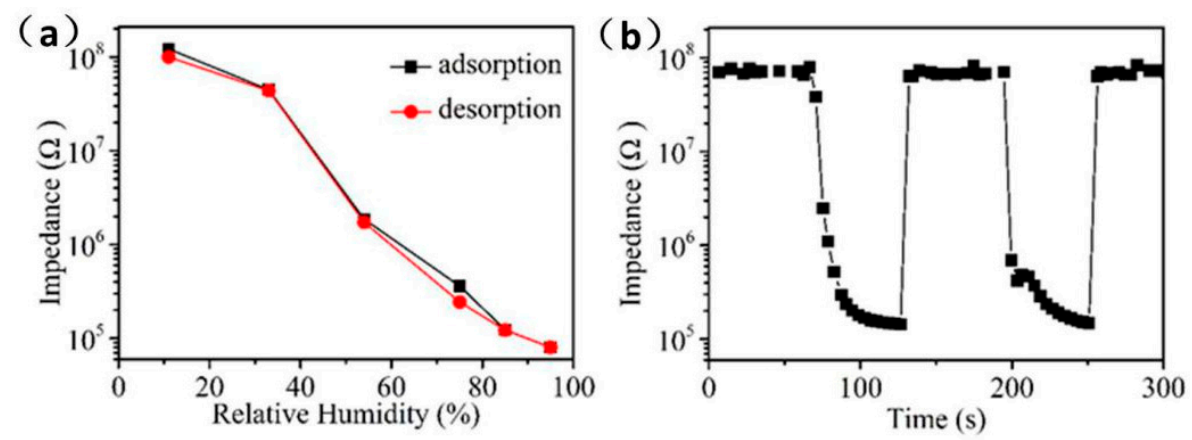

Figure 7. Ag/ZnO-2 humidity sensor (a) hysteresis, (b) response/recovery time and repeatability test.

Figure 8 shows the resistance response curve under different lights. This section studies the effects of light with different wavelength on the resistance of $\mathrm{Ag} / \mathrm{ZnO}-2$ and judges the sensing characteristics of the humidity sensor from the situation of the resistance response curve, taking into account that the use of different illuminations can make the surface of the sample obtain a certain amount of energy, and that a small amount of photoelectrons may be generated on the surface of the sample, thereby increasing the conductivity of $\mathrm{ZnO}$. In the experiments, visible ( $5 \mathrm{~W})$, red $(5 \mathrm{~W}, 546 \mathrm{~nm})$, blue ( $5 \mathrm{~W}$, $465 \mathrm{~nm}$ ), and ultraviolet light ( $5 \mathrm{~W}, 365 \mathrm{~nm}$ ) were used to illuminate $\mathrm{Ag} / \mathrm{ZnO}-2$ sensors at different relative humidity. We found that in the absence of light, the sensors showed the best response and the best linearity, reflecting that the light affects the performance of the $\mathrm{Ag} / \mathrm{ZnO}-2$ humidity sensor, and in the absence of lighting, the synthesis cost of the sensor can undoubtedly be reduced.

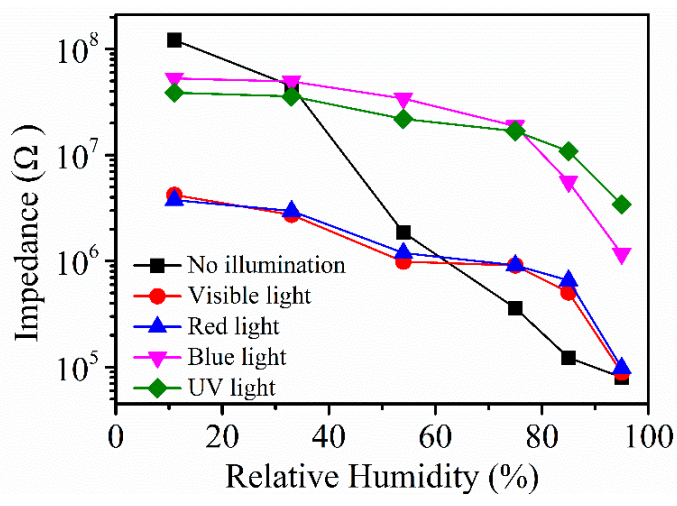

Figure 8. Ag/ZnO-2 resistance response curve under different light.

The humidity sensing mechanism of $\mathrm{Ag} / \mathrm{ZnO}-2$ was studied by complex impedance spectra, as show in Figure 9. At low humidity $(11 \%, 33 \%, 54 \% \mathrm{RH})$, complex impedance spectrum approaches a semicircular shape. In this process, a small amount of water molecules is adsorbed on $\mathrm{Ag} / \mathrm{ZnO}$ surface in forms of physical and chemical adsorption. The rich oxygen vacancies on the $\mathrm{Ag} / \mathrm{ZnO}-2$ surface can accelerate the dissociation of adsorbed water molecules into $\mathrm{OH}^{-}$and $\mathrm{H}^{+}$. At this time, a small amount of $\mathrm{H}_{3} \mathrm{O}^{+}$will be formed, and the protons will conduct jump on the $\mathrm{Ag} / \mathrm{ZnO}$ surface. When the humidity reaches $75 \%, 85 \%$ and $95 \% \mathrm{RH}$, complex impedance spectrum becomes smaller in the semicircle in low frequency region and a straight line gradually appears at the tail. At this time, when a large amount of water molecules is adsorbed on $\mathrm{Ag} / \mathrm{ZnO}-2$ surface in the form of chemisorption, a continuous water film is formed. With the increasing number of water molecules and the formation of an ion transport mechanism, $\mathrm{H}_{3} \mathrm{O}^{+}$continues to migrate onto the surface of the material, enhancing conductivity of the material, thereby improving the performance of the sensor. 

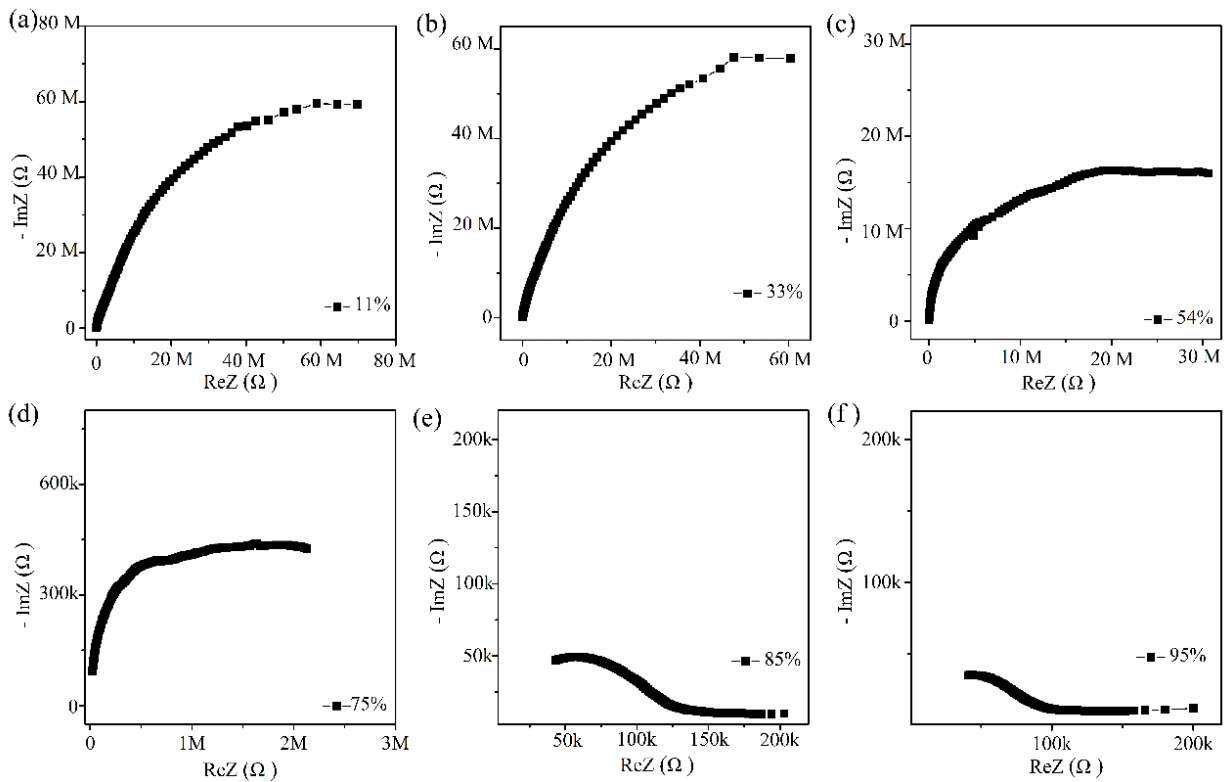

Figure 9. (a-f) Complex impedance spectroscopy of $\mathrm{Ag} / \mathrm{ZnO}-2$ humidity sensor from $11 \% \mathrm{RH}$ to $95 \%$ RH (k refers to $10^{3}$ and $\mathrm{M}$ refers to $10^{6}$ ).

\section{Conclusions}

An Ag modified $\mathrm{ZnO}$ humidity sensor was successfully prepared, and effects of different $\mathrm{Ag}$ concentration on performance of the humidity sensor was studied. Experimental results show that when the molar ratio of $\mathrm{Ag}^{+}: \mathrm{Zn}^{2+}$ in the sample is 1:100, the uniformly distributed $\mathrm{Ag}$ particles on $\mathrm{ZnO}$ make $\mathrm{ZnO}$ have abundant active sites on the surface and more oxygen vacancies, which can capture more water molecules and accelerate the decomposition to form conductive ions, thereby increasing the humidity of $\mathrm{Ag} / \mathrm{ZnO}-2$ sensor performance. In the range of relative humidity from $11 \%$ to $95 \%, \mathrm{Ag} / \mathrm{ZnO}$ humidity sensor shows better response $(151,800 \%)$, smaller lag error $(3 \%)$, faster response and recovery time $(36 / 6 \mathrm{~s})$ and better repeatability. This research has laid the foundation for the development of high-performance metal semiconductor humidity sensors, which are expected to be used for efficient measurement of moisture in the environment.

Author Contributions: H.Z. and P.L. conceived and designed the experiments; P.L. and S.Y. performed the experiments; H.Z. and P.L. analyzed the data; S.Y. Contributed reagents/materials/analysis tools; P.L., S.Y. and H.Z. wrote the paper. All authors have read and agreed to the published version of the manuscript.

Funding: This work was supported by the National Science Foundation of China (No. 61665011) and Xinjiang University Doctoral Research Initiation Project (No. BS180212).

Institutional Review Board Statement: Not applicable for studies not involving humans or animals.

Informed Consent Statement: Not applicable for studies not involving humans.

Data Availability Statement: Data available in a publicly accessible repository.

Conflicts of Interest: The authors declare no conflict of interest.

\section{References}

1. Modaresinezhad, E.; Darbari, S. Realization of a room-temperaturelf-powered humidity sensor, based on $\mathrm{ZnO}$ nanosheets. Sens. Actuators B Chem. 2016, 237, 358-366. [CrossRef]

2. Zhao, Y.; Yang, B.; Liu, J. Effect of interdigital electrode gap on the performance of $\mathrm{SnO}_{2}$-modified $\mathrm{MoS}_{2}$ capacitive humidity sensor. Sens. Actuators B Chem. 2018, 271, 256-263. [CrossRef]

3. Zhang, D.; Tong, J.; Xia, B. Ultrahigh performance humidity sensor based on layer-by-layerself-assembly of graphene oxide/polyelectrolyte nanocomposite film. Sens. Actuators B 2014, 203, 263-270. [CrossRef] 
4. Alessandro, D.M.; Maria, E.F.; Vittorio, P.; Giuliana, I. ZnO for application in photocatalysis: From thin films to nanostructures. Mater. Sci. Semicond. Process. 2017, 69, 44-51.

5. Rajbongshi, B.M.; Samdarshi, S.K. ZnO and Co-ZnO nanorods-complementary role of oxygen vacancy in photocatalytic activity of under UV and visible radiation flux. Mater. Sci. Eng. B 2014, 182, 21-28. [CrossRef]

6. Senapati, M.; Sahu, P. Meat quality assessment using Au patch electrode $\mathrm{Ag}-\mathrm{SnO}_{2} / \mathrm{SiO}_{2} / \mathrm{Si}$ MIS capacitive gas sensor at room temperature. Food Chem. 2020, 324, 126893. [CrossRef]

7. Du, W.; Si, W.; Du, W. Unraveling the promoted nitrogen dioxide detection performance of $\mathrm{N}$-doped $\mathrm{SnO}_{2} \mathrm{microspheres}$ at low temperature. J. Alloy Compd. 2020, 834, 155209. [CrossRef]

8. Song, J.; Huang, M.; Jiang, N. Ultrasensitive detection of amoxicillin by $\mathrm{TiO}_{2}-\mathrm{g}-\mathrm{C}_{3} \mathrm{~N}_{4} @$ AuNPs impedimetric aptasensor: Fabrication, optimization, and mechanism. J. Hazard. Mater. 2020, 391, 122024. [CrossRef]

9. Kumar, V.; Chauhan, V.; Ram, J. Study of humidity sensing properties and ion beam induced modifications in $\mathrm{SnO}_{2}-\mathrm{TiO}_{2}$ nanocomposite thin films. Surf. Coat. Tech. 2020, 392, 125768. [CrossRef]

10. Qi, Q.; Wang, Q.; Liu, N. A Novel Nanorod Self-Assembled $\mathrm{WO}_{3}$ center dot $\mathrm{H}_{2} \mathrm{O}$ spherical structure: Preparation and flexible gas sensor. J. Nanosci. Nanotechnol. 2020, 20, 4746-4752. [CrossRef]

11. Wang, M.; Wang, Y.; Li, X. $\mathrm{WO}_{3}$ porous nanosheet arrays with enhanced sensing performance low temperature $\mathrm{NO}_{2}$ gas. Sens. Actuators B Chem. 2020, 316, 128050. [CrossRef]

12. Cao, P.J.; Huang, Q.G.; Navale, S.T. Integration of mesoporous $\mathrm{ZnO}$ and Au@ZnO nanospheres into sensing device for the ultrasensitive $\mathrm{CH} 3 \mathrm{COCH} 3$ detection down to ppb levels. Appl. Surf. Sci. 2020, 518, 146223. [CrossRef]

13. Dwiputra, M.A.; Fadhila, F.; Imawan, C. The enhanced performance of capacitive-type humidity sensors based on ZnO nanorods $/ \mathrm{WS}_{2}$ nanosheets heterostructure. Sens. Actuators B Chem. 2010, 310, 127810. [CrossRef]

14. Tomer, V.K.; Duhan, S.; Sharma, A.K.; Malik, R.; Nehra, S.P.; Devi, S. One pot synthesis of mesoporous $\mathrm{ZnO}-\mathrm{SiO}_{2}$ nanocomposite as high performance humidity sensor. Colloids Surf. A 2015, 483, 121-128. [CrossRef]

15. Hsueh, H.T.; Hsueh, T.J.; Chang, S.J.; Hung, F.Y.; Tsai, T.Y.; Weng, W.Y.; Hsu, C.L.; Dai, B.T. CuO nanowire-based humidity sensors prepared on glass substrate. Sens Actuators B 2011, 156, 906-911. [CrossRef]

16. Zainelabdin, A.; Amin, G.; Zaman, S.; Nur, O.; Lu, J.; Hultman, L.; Willander, M. CuO/ZnO nanocorals synthesis via hydrothermal technique: Growth mechanism and their application as humidity sensor. J. Mater. Chem. 2012, 22, 11583-11590. [CrossRef]

17. Wang, Z.L. Zinc oxide nanostructures: Growth, properties and applications. J. Phys. Condens. Matter. 2004, 16, 829-858. [CrossRef]

18. Spanhel, L. Colloidal ZnO nanostructures and functional coatings: A survey. J. Sol Gel Sci. Technol. 2006, 39, 7-24. [CrossRef]

19. Sharma, D.; Jha, R. Transition metal (Co, Mn) co-doped ZnO nanoparticles: Effect on structural and optical properties. J. Alloy Compd. 2017, 698, 532-538. [CrossRef]

20. Chand, P.; Gaur, A.; Kumar, A.; Gaur, U.K. Effect of NaOH molar concentration on optical and ferroelectric properties of ZnO nanostructures. Appl. Surf. Sci. 2015, 356, 438-446. [CrossRef]

21. Yu, S.; Zhang, H.; Chen, C.; Zhang, J.; Li, P. Preparation and mechanism investigation of highly sensitive humidity sensor based on two-dimensional porous Gold/Graphite carbon nitride nanoflake. Sens. Actuators B Chem. 2020, 307, 127679. [CrossRef]

22. Yu, S.; Zhang, H.; Chen, C.; Lin, C. Investigation of humidity sensor based on Au modified ZnO nanosheets via hydrothermal method and first principle. Sens. Actuators B Chem. 2019, 287, 526-534. [CrossRef]

23. Zhang, Y.; Chen, Y.; Zhang, Y.; Cheng, X.; Feng, C.; Chen, L.; Zhou, J.; Ruan, S. A novel humidity sensor based on $\mathrm{NaTaO}_{3}$ nanocrystalline. Sens. Actuators B Chem. 2012, 174, 485-489. [CrossRef]

24. Gong, M.; Li, Y.; Guo, Y.; Lv, X.; Dou, X. $2 \mathrm{D} \mathrm{TiO}_{2}$ nanosheets for ultrasensitive humidity sensing application benefited by abundant surface oxygen vacancy defects. Sens. Actuators B Chem. 2018, 262, 350-358. [CrossRef]

25. Pawbake, A.S.; Waykar, R.G.; Late, D.J.; Jadkar, S.R. Highly transparent wafer-scale synthesis of crystalline $\mathrm{WS}_{2}$ nanoparticle thin film for photodetector and humidity-sensing applications. ACS Appl. Mater. Interfaces 2016, 8, 3359-3365. [CrossRef]

26. Kuntal, D.; Chaudhary, S.; Kumar, A.B.V.K.; Megha, R.; Ramana, C.V.V.; Kiran, Y.T.R.; Thomas, S.; Kim, D. rGO/ZnO nanorods/Cu based nanocomposite having flower shaped morphology: Ac conductivity and humidity sensing response studies at room temperature. J. Mater. Sci. Mater. Electron. 2019, 30, 15544-15552. [CrossRef]

27. Zhang, M.; Zhang, H.; Li, L.; Tuokedaerhan, K.; Jia, Z. Er-enhanced humidity sensing performance in black zno-based sensor. J. Alloy Compd. 2018, 744, 364-369. [CrossRef]

28. Wang, Y.; Park, S.; Yeow, J.T.W.; Langner, A.; Muller, F. A capacitive humidity sensor based on ordered macroporous silicon with thin film surface coating. Sens. Actuators B Chem. 2010, 149, 136-142. [CrossRef]

29. Feng, M.H.; Wang, W.C.; Li, X.J. Capacitive humidity sensing properties of CdS/ZnO sesame-seed-candy structure grown on silicon nanoporous pillar array. J. Alloy Compd. 2017, 698, 94-98. [CrossRef] 